\title{
PROSPECTS FOR THE USE OF SCIENTIFIC AND TECHNICAL MEANS DURING THE PRE-TRIAL INVESTIGATION IN THE CONTEXT OF TECHNICALIZATION AND DIGITALIZATION OF SOCIETY
}

\author{
Anastasiia Korchahina \\ Postgraduate Student at the Department of Branch Law, Kherson State University, Ukraine \\ e-mail: stasykorchahina@gmail.com,orcid.org/0000-0001-5483-7461
}

\section{Summary}

The article examines various aspects of the application of special knowledge and scientific and technical means in criminal proceedings, including at the stage of pre-trial investigation.

The development of science and technology creates significant conditions and opportunities to ensure the completeness, comprehensiveness and objectivity of pre-trial and judicial investigation in specific criminal cases, in general, contribute to improving the scientific, technical and methodological level of investigative and judicial activities. Therefore, today it is especially important to find new ways to solve long-standing problems of improving the activities for the detection and investigation of crimes and ensuring the inevitable responsibility for their commission.

Digitalization and technicalization of public life leads to the emergence of new ways of committing criminal offenses, and hence to the development and improvement of methods, techniques and tools for their prevention, detection and investigation.

The author focuses on the possibilities of using data obtained from the Internet on pages in social networks to ensure the collection of evidence for the investigation and detection of criminal offenses. Emphasizes the importance of training and methodological support for law enforcement officers on the detection, reading, storage and reproduction of information obtained from technical devices.

The author also considers the improvement of audio, photo and video surveillance systems in public places to be promising. Studies show that video surveillance systems are effective preventive measures, as well as response measures to protect citizens and ensure a sense of security.

Keywords: scientific and technical means, forensic means, investigation, forensic equipment, criminal proceedings.

DOI: https://doi.org/10.23856/4027

\section{Introduction}

In recent years, we have seen a rapid level of implementation of technical means in all spheres of life: life and leisure, work, study, banking and medical, security systems (from mobile devices to the protection of buildings and facilities of national importance). The technologicalization and digitalization of modern society not only simplifies everyday life, but can also help detect, investigate and prevent criminal offenses.

The purpose of the article is to study the prospects of using scientific and technical means at the stage of pre-trial investigation, as well as to prevent criminal offenses. 


\section{The importance of scientific and technical means in the detection of crimes}

One of the priorities of state policy is to ensure the rights and freedoms of man and citizen, as well as the creation of an appropriate system of organs and a mechanism to protect his life and health. For the implementation of this postulate, not only the legislative basis has been created, but also an effective system of state bodies, the main task of which is the fight against criminal acts.

As rightly noted by H. Karpov one of the main areas of improving methods and means of combating crime is the full use of scientific and technological progress, establishing clear and effective legal rules to combat crime, increasing the level of logistics and staffing of law enforcement agencies (Karpov, 2008: 20).

For the detection and investigation of criminal offenses and crimes are important those technical means that can leave a mark (in any form) on the actions (activities) of the subject of the offense.

That is why there is a need to develop and implement in the activities of law enforcement agencies practical algorithms for studying the systemic environment of criminal activity, traces of which can be reflected in the means of general technical (non-criminal) purpose. Such means include technical devices that, acting as an element of the material structure of the crime, are able to retain new types of human reflections: payment terminals, kiosks, ATMs, mobile phones, 3G modems, audio and video surveillance systems, drones, car DVRs, audio - and video systems, call recording systems, Internet search queries, data received by voice assistants in mobile devices, information from GPS navigators, digital television, etc.

Our research revealed several promising areas of use of information technology in the detection of criminal offenses: 1) search for information about the preparation and / or commission of a crime, as well as the consequences of criminal activity; 2) search for persons who have committed a criminal offense (organizers, accomplices, intermediaries, etc.).

\section{Means of searching and obtaining information about the crime}

Regarding the first point, monitoring of publicly available information obtained from social networks (VKontakte, Odnoklassniki, Facebook, Instagram, Twitter, YouTube, etc.) can be effective. This allows not only to quickly establish social ties, financial and marital status, but also to put forward versions of places of recreation and illegal activities, the availability of property, vehicles and more.

In the United States, this type of information, and therefore the evidence obtained using it, is increasingly referred to as "digital evidence", defining it as information that is "stored or transmitted in binary form that can be referenced in court." (Novak, M., Grier, J., Gonzales, D. 2018).

With the main task of combating crime, law enforcement agencies, collecting and analyzing digital evidence, create, in fact, a new branch of forensic knowledge - computer forensics. This poses a new challenge to law enforcement: the need to develop and implement effective methods of collecting, processing, storing digital evidence, and the need to "keep up" with rapid technological progress and computer operating systems.

It is also important to note that tracking the activities and activities of individual users or communities on the Internet is not only a tool for finding information about their activities, but also allows you to involve a significant audience of users in the search for criminals. This position is also supported by the National Police of Ukraine, and is confirmed by the slogan posted 
on the website of the Ministry of Internal Affairs of Ukraine: "The correct position of a citizen is to help with evidence in the search for criminal elements" (Ministry of Internal Affairs).

Obtaining information about the crime and the identity of the offender (criminals) can be done through photo and video surveillance.

Today, the streets of almost all relatively large cities in Europe and America are equipped with video cameras, which are used by law enforcement agencies to maintain order, to analyze and solve crimes. The leader in this field is the United Kingdom, which was one of the first in the world to use video surveillance to ensure the safety of citizens and to introduce the latest technical means for more efficient work of its law enforcement agencies. The case law of the European Court of Human Rights is also in favor of the significance of the data obtained from the means of recording.

Witness testimony is an important area of research in the field of cognitive psychology and human memory. Both at the pre-trial stage and in the trial, the competent authorities (investigators, investigating judges, judges and jurors) tend to trust the testimony of witnesses and usually consider them as a reliable source of information when it comes to identifying criminals or discussing details of the crime. However, it should be emphasized that witness testimony is individual memories that have been formed and constructed in accordance with personal stereotypes, beliefs and expectations. Even CCTV footage can be interpreted differently depending on the viewer, his life and professional experience. However, the main advantage of the videos is the ability to capture aspects of the incident that were missed by witnesses at the scene.

Installation of video surveillance cameras in public places will increase the level of detection of offenses (administrative and criminal). Thus, in 2018, the Kyiv Police uncovered more than 2,500 crimes with the help of so-called "smart cameras" of video surveillance with the function of face recognition and license plates. With their help, the most serious crimes were revealed - murders, kidnappings, robberies and burglaries. For example, an attack on a jewelry store was uncovered when, in August, gunmen killed a security guard and confiscated jewelry (Ukrainska Pravda). Although a small number of CCTV cameras have been installed in Ukraine so far, they bring real benefits to law enforcement, helping to uncover numerous crimes, which the ECtHR also draws attention to.

\section{Possibilities of gadgets in crime detection}

The widespread use of various gadgets in the commission of criminal offenses determines the need to obtain the information contained in them. Research of the information content of a mobile phone, SIM-card, memory card can be complicated by various circumstances: lack of sufficient experience in handling these objects; the need to involve specialists and experts to extract and preserve the obtained forensically significant information; insufficient level of software and hardware, etc.

These problems can be solved thanks to modern scientific and technical means. For example, Oxygen Forensics is the world's leading provider of digital forensics software, providing law enforcement, federal agencies and businesses with access to critical data and analytics. Oxygen Forensics ${ }^{\circledR}$ specializes in mobile devices, cloud storage, drones and provides state-of-the-art digital data retrieval tools as well as analytical tools for criminal and corporate investigations. In particular, the program Oxygen forensic ${ }^{\circledR}$ detective, has the ability to find passwords to encrypted backups and images of devices; bypasses screen lock on popular Android devices; receives data from cloud services and repositories; extracts flight history and media files from drones; receives data from devices connected to the Internet and smart 
watches; collects user data on PCs with Windows, MacOS and Linux; supports import and analysis of call data records; recognizes optical symbols, faces and images; provides analysis of social links and revision of the timeline (Oxygen forensics).

Therefore, using the information obtained, it is possible to track, for example, the financial transactions of the offender, his correspondence or location for a certain period, to identify accomplices and accomplices, and so on.

It should be noted that such an intervention must have sufficient legal grounds and be carried out in compliance with the rights and legitimate interests of man and citizen. Abuse of the right of access to such information must be ruled out, as well as all procedural and factual measures to ensure the confidentiality of information of the victim, suspect, accused, convicted person.

\section{Using of the latest technologies at the scene}

Conducting an inspection of the scene requires the staff of the investigative task force to be accurate and efficient. You often have to work in tight spaces, for a limited period, to deal with fragile or perishable objects, as well as in conditions where the situation of the scene is subject to rapid change (weather conditions, condition of the room or road surface etc.). That is why it is advisable to supplement with innovative means of measuring and reproducing the surrounding space, such as a three-dimensional ground-based laser scanner (3D scanner), along with the use of traditional scientific and technical means of recording evidence (rulers, tape measures, cameras, tacheometers, etc.). Because of application of such technology, the received information on spatial objects at investigative inspection is as much as possible, full and exact. A clear and structured representation of the scene will help build the most plausible investigative versions and spatial reproduction of the crime scene.

It is also worth paying attention to the possibility of introducing a portable X-ray television installation during inspections and searches, measures to identify hidden objects, including hiding places. High technical characteristics allow identifying hidden objects with a higher degree of probability.

The use of the achievements of science and technology in criminal procedure creates such social relations that require regulation. Firstly, this is due that the provisions of the Criminal Procedure Code regulated all activities for the investigation of criminal cases in detail. Secondly, criminal investigation activities are exclusively legal in nature and the procedure and conditions for using the achievements of science and technology in the investigation of crimes must have a legal basis.

In addition, an important component of attracting new scientific and technical means at the stage of pre-trial investigation is the appropriate training of staff of competent authorities.

\section{Conclusions}

Thus, due to the rapid development of technology and its use for the investigation and detection of criminal offenses, the legislature is faced with the need to both constantly amend and clarify the current criminal procedure legislation. They must develop such criminal procedure rules that would ensure universal and relatively stable regulation of the use of scientific and technological progress in criminal procedure.

Continuous improvement of the scientific and methodological level of crime investigation is one of the functions of forensic science, which requires a special service of scientific and 
methodological support, designed to facilitate, firstly, the implementation of scientific recommendations, and secondly, optimize their application.

It is necessary to emphasize the need for active cooperation at the interstate level and exchange of experience in both theoretical, methodological and practical knowledge for the experience of prevention, investigation and detection of criminal offenses.

\section{References}

Karpov, N. (2008) Kryminalistychni zasady vyvchennia zlochynnoi diialnosti [Criminalistic basis for studying the criminal activit]. (PhD Thesis). Kyiv : Kyivskyi natsionalnyi universytet vnutrishnikh sprav.

Ministry of Internal Affairs. (2020). Osoby, yaki perekhovuiutsia vid orhaniv vlady [Persons hiding from the authorities]. Retrieved from: https://wanted.mvs.gov.ua/searchperson (accessed 20 September 2020)

Novak M., Grier J., Gonzales D. (2018, October 7). «New Approaches to Digital Evidence Acquisition and Analysis». NIJ Journal (electronic journal), No. 280, pp. 1-8. Retrieved from: https://nij.ojp.gov/topics/articles/new-approaches-digital-evidence-acquisition-and-analysis\#citation--0 (accessed 20 September 2020)

Oxygen forensics (2020). Retrieved from https://www.oxygen-forensic.com/en/products/oxygen-forensic-detective [in English]. (accessed 18 September 2020)

Ukrainska Pravda. Za dopomohoiu "rozumnykh" kamer u Kyievi za rik rozkryly 2,5 tysiachi zlochyniv [In Kyiv 2,500 crimes were solved in a year with the help of "smart" cameras] (2018, November 1). (electronic journal). Retrieved from https://www.pravda.com.ual news/2018/11/1/7196935/(accessed 19 September 2020) 